\title{
PERANCANGAN BRANDING LOGO DIMSUM DAN BAKSOTAHU TITIANZHUA SEBAGAI MAKANAN CEMILAN KOTA MEDAN
}

\section{Titin Setiawati}

Prodi Desain Komunikasi Visual Fakultas Seni dan Desain Universitas Potensi Utama Medan titianmee@gmail.com

\begin{abstract}
ABSTRAK
Dimsum Titianzhua merupakan olahan makanan berupa bakso, taiso (tahu isi bakso) dan Dimsum yang di buat di rumah, penjualannya melalui media sosial seperti BBM, facebook, intsagram. Pemasanan bebas biaya antar jika pembeli berada di sekitaran daerah produksi. Harga bakso dan taiso lima ribu rupiah perbungkus yang berisi sepuluh buah dan di bungkus dengan plastik setengah kilogram yang memiliki rasa ayam dan ikan. Dimsum isi enam dan satu bungkus saus dengan harga lima belas ribu perbungkus dan dibungkus dengan plastik mika yang memiliki rasa ayam bercampur udang namun lebih terasa udang. Logo sangatlah hal yang akan menjadikan sebuah Brand bias dikenal oleh seluruh masyarakat, oleh karena itu penulis ingin membranding logo tersebut agar produk yang dipasarkan semakin dikenal oleh masyarakat.
\end{abstract}

Kata Kunci : Perancangan Branding, Logo Dimsum, Cemilan Kota Medan

\begin{abstract}
Titianzhua Dimsum is a processed food in the form of meatballs, taiso (tofu meatball contents) and Dimsum which are made at home, selling through social media such as BBM, facebook, intsagram. Pemasanan is free of charge between if the buyer is in the vicinity of the production area. The price of five thousand rupiahs of meatballs and taiso wrapped in ten pieces and wrapped in a half-kilogram plastic with chicken and fish flavor. Dimsum contains six and one packet of sauce at a price of fifteen thousand packs and wrapped in mica plastic which has chicken flavor mixed with shrimp but more prawn. The logo is the thing that will make a brand known to the whole community, therefore the author wants to compare the logo so that the products marketed are increasingly recognized by the public.
\end{abstract}

Keywords : Branding Design, Logo Dimsum, Medan Snacks

\section{PENDAHULUAN}

Logo adalah sebuah merek atau brand. Logo adalah sebuah yang diwakilkan dari perusahaan. Dengan adanya sebuah logo maka akan menjadi pembeda antara usaha sendiri dengan usaha yang lainnya. Oleh karena itu kita harus menciptkan sebuah logo yang bisa membuat masyarakat tertarik dan sangat mudah untuk diingat. 
Dimsum Titianzhua adalah cemilan yang terbuat dari daging ayam yang dicampur dengan udang, serta baksotahu yang dibuat dengan olahan bakso daging ikan dengan dibalut tahu. Selama ini penjual hanya memasarkan produknya melalui media sosial seperti, facebook,serta instagram. Pemilik dari usaha Dimsum Titianzhua ini adalah Saya Sendiri yaitu Titin Setiawati, Dimsum Titianzhua beralamat jalan Veteran Pasar delapan gang Melati Dusun Lima Desa Manunggal Helvetia Medan. Disini saya ingin masyarakat lebih mengenal produk yang saya buat. Dalam hal ini Dimsum Titian Zhua belum memiliki sebuah logo resmi sebagai identitas dirinya, maka dari itu saya sebagai penulis sekaligus desainer ingin mendesain logo dari Dimsum TitianZhua tersebut. Karena dengan adanya logo yang akan dibuat bisa menjadikan produk lebih memiliki nilai jual yang lebih lagi.

Dizaman yang semakin pesat oleh perkembangan teknologi ini kita harus bisa menjadikan hobi kita untuk dijadikan mata pencarian, akan tetapi hal itu tidak akan cukup untuk bisa memajukan atau memperkenalkan produk yang kita punya. Oleh sebab itu kita harus mempunyai ciri khas logo usaha kita sendiri.

\section{STUDI LITERATUR}

Desain berasal dari bahasa asing. Yang berasal dari bahasa itali "designo" yang berarti gambar. Sedangkan didalam bahasa inggris "design" yang mempunyai arti rancang, rancangan atau merancang. Makna ini dinilai kurang mengekspresikan keilmuan, keluasan, dan kewibawaan profesi terhadap seorang desainer. Akhirnya, para insinyur menggunkan istilah rangcang bangun terhadap pengganti istilah desain. Dengan adanya hal tersebut, beberapa ilmuan seni rupa dan desain, istilah desain tetap secara ketetapannya dan formal mempergunakannya. Dalam dunia seni rupa istilah desain terpadukan dengan reka bentuk, reka rupa, rancangan atau sketsa ide.

Menurut Kamus Besar Bahasa Indonesia arti kata Desain adalah sebuah bentuk; rancangan; motif; pola; corak.

Henricus Kusbiantoro mengakatan bahwa desain adalah kompromi antara seni dan bisnis. Yaitu melayani kebutuhan orang banyak pada pemecahan problem visual, namun sekaligus tidak kehilangan karakter dan keunikan dari segi eksekusi visual baik konsep maupun visual teknis.

Menurut Agus Sachari (2005:7) desain adalah sebuah ilustrasi dari apa yang kita lihat setelah itu kita menuangkannya kedalam sebuah desain melalui penglihatan kita. Desain merupakan suatu bentuk kebutuhan kepada badani dan rohani manusia yang dijabarkan terhadap berbagai bidang pengalaman, skill, serta pengetahuannya yang mencerminkan perhatian terhadap apresiasi serta adaptasi terhadap sekelilingnya, terutama dalam keterkaitan dengan bentuk, komposisi, arti, nilai, serta berbagai tujuan benda buatan manusia (Archer, 1976).

Desain merupakan kreatifitas dalam mencerminkan keanekaan bentuk kualitas serta sistem, yang memiliki keterkaitan dengan lingkaran. Selain itu, desain merupakan faktor yang membangun kegiatan inovasi pemanusiaan teknologi, dinamika budaya, dan perubahan ekonomi (ICSID,1999). 
Secara sederhana desain merupakan bagian pola rancangan yang menjadi dasar pembuatan terhadap suatu benda. Desain merupakan langkah awal sebelum memulai membuat suatu benda, seperti baju, furniture, bangunan, logo, poster, dan sebagainya. Awal pembuatan desain dimulai dengan memasukkan unsur berbagai pertimbangan, perhitungan dan cita rasa, sehingga bisa dibilang bahwa sebuah desain merupakan bentuk perumusan dari berbagai unsur termasuk berbagai macam pertimbangan di dalamnya.

Berdasarkan defenisi para ahli di atas, dapat disimpulkan bahwa desain adalah suatu kegiatan kreatifitas yang menghasilkan sebuah rancangan ataupun hasil yang menjadikan sebuah karya menjadi inovatif sesuai dangan keilmuan dan profesi khusus yang dijalani dan memiliki prinsip dan unsur yang sama terhadap suatu desain.

Logo merupakan singkatan dari logotype. Istilah logo baru muncul tahun 1937 dan kini istilah logo lebih populer daripada logotype. Logo bisa menggunakan sebuah elemen apa saja, berupa tulisan, logogram, gambar, ilustrasi, dan lain-lain. Banyak juga yang mengatakan logo adalah sebuah elemen gambar/ simbol pada identitas visual. (Rustan, 2009: 13).

\section{PEMBAHASAN}

\section{III.1. Metode Perancangan}

Untuk memperoleh hasil perancangan logo dari Dimsum Titianzhua yang komunikatif dan efektif, dan mampu mencapai tujuan, maka diperlukan sebuah metode yang baik untuk mewujudkannya.

Metode Perancangan logo Dimsum Titianzhua ini dikelompokkan menjadi empat tahap, yaitu :

a. Tahap Observasi dan Identifikasi Data

Tahap ini meliputi pengumpulan data tentang seluruh aspek yang berkaitan dengan Dimsum Titianzhua, khususnya masalah produk apa saja yang di jual di Dimsum Titianzhua. Hal ini meliputi nama makanan, bahan-bahan untuk membuat produk, proses pembuatan, harga, cara dan model kemasan dan cara pemasarannya

b. Tahap Analisis (pembahasan)

Pada tahap ini data-data yang telah didapat, dianalisa kembali dengan menggunakan metode analisis $5 \mathrm{~W}+1 \mathrm{H}$. Hal ini bertujuan agar logo yang dirancang dapat berkomunikasi dengan baik kepada audience.

c. Tahap pembuatan karya (art work)

Tahap ini merupakan tahap akhir apabila semua data dan ide serta konsep dirasa sudah layak untuk diracik menjadi sebuah karya.

\section{III.2. Ruang Lingkup Perancangan}

Agar pembahsan dalam perancangan tidak meluas dan agar tidak mengurangi tujuan yang ingin di capai, maka perlu adanya pembatas ruang lingkup di dalam perancangan logo Dimsum Titianzhua ini. Ruang lingkup perancangan di batasi pada pencarian data seputar Dimsum Titianzhua, visi dan misi, dan bertanya kepada pembeli dan pelanggan Dimsum Titianzhua, dan letak geografis yang berada di jalan Veteran pasar delapan gang Melati 
Dusun lima Desa Manunggal Helvetia Medan. Kegiatan perancangan nantinya meliputi proses pembuatan sketsa sebanyak 50 gambar yang kemudian akan di pilih yang terbaik, setelah itu dari sketsa yang ada, dibuat desain digitalnya menggunakan komputer kemudian pemilihan logo digital yang terbaik yang akan di aplikasikan ke dalam beberapa benda seperti kotak, bungkus plastik pin dan lain-lain, .

Target dalam perancangan ini adalah semua kalangan masyarakat, yang mana masyarakat yang menjadi target adalah sebagai berikut:

\section{Demografis}

Usia $\quad: \sim$ tahun

Terdiri dari : Anak-anak, Remaja, dewasa, orang tua

Jenis kelamin : laki-laki dan perempuan

2. Geografis

3. Pisikografi

Lokasi sasaran yang dituju dalam perancangan ini adalah kota Medan.

Secara target perancangan ini akan di letakkan di rumah produksi itu sendiri, kemudian akan di sebar memalui pembagian brosur dan pembuatan plank nama di pinggir jalan.

\section{III.3. Metode Pengumpulan Data}

\section{a. Data verbal}

\section{b. Data verbal}

1) Wawancara

Melakukan wawancara dengan bertanya kepada beberapa sumber, dengan melakukan wawancara yang terstruktur, data yang di peroleh berkaitan dengan informasi seputar Dimsum Titianzhua, wawancara dilakukan dengan karyawan Dimsum Titianzhua, dan tidak lupa pula bertanya kepada pembeli dan pelanggan setia Dimsum Titianzhua.

2) Observasi

Observasi yang di lakukan adalah dengan terjun langsung kelapangan mengunjungi Dimsum Titianzhua yang ada pada jalan Veteran Pasar Delapan Gang Melati Nomor 096 Dusun Lima Desa Manunggal Helvetia Medan.

\section{c. Data Visual}

Mencari sumber informasi berupa foto, dokumen dan data tentang Dimsum Titianzhua. 


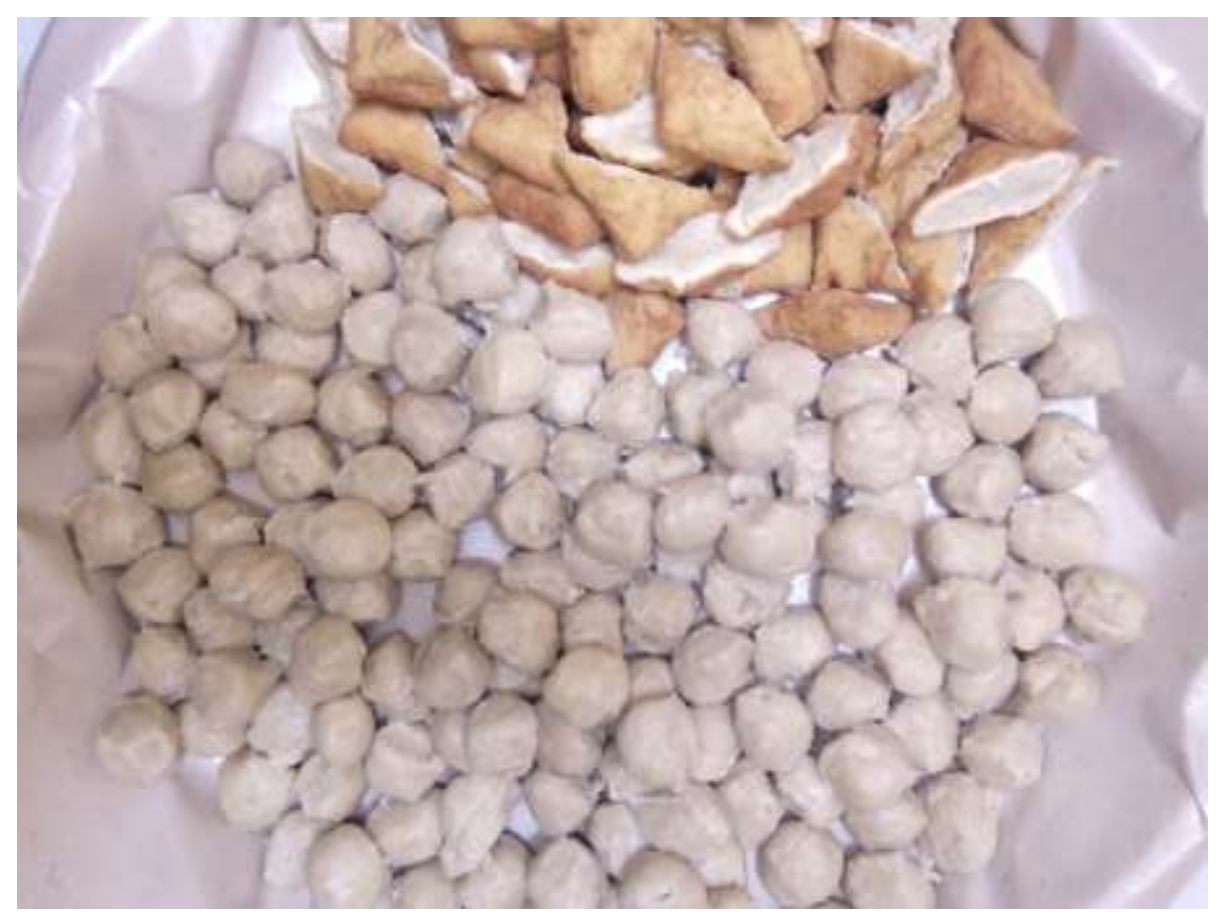

Gambar 1. Baksotahu Titianzhua

(Sumber. Titin Setiawati. 2015)

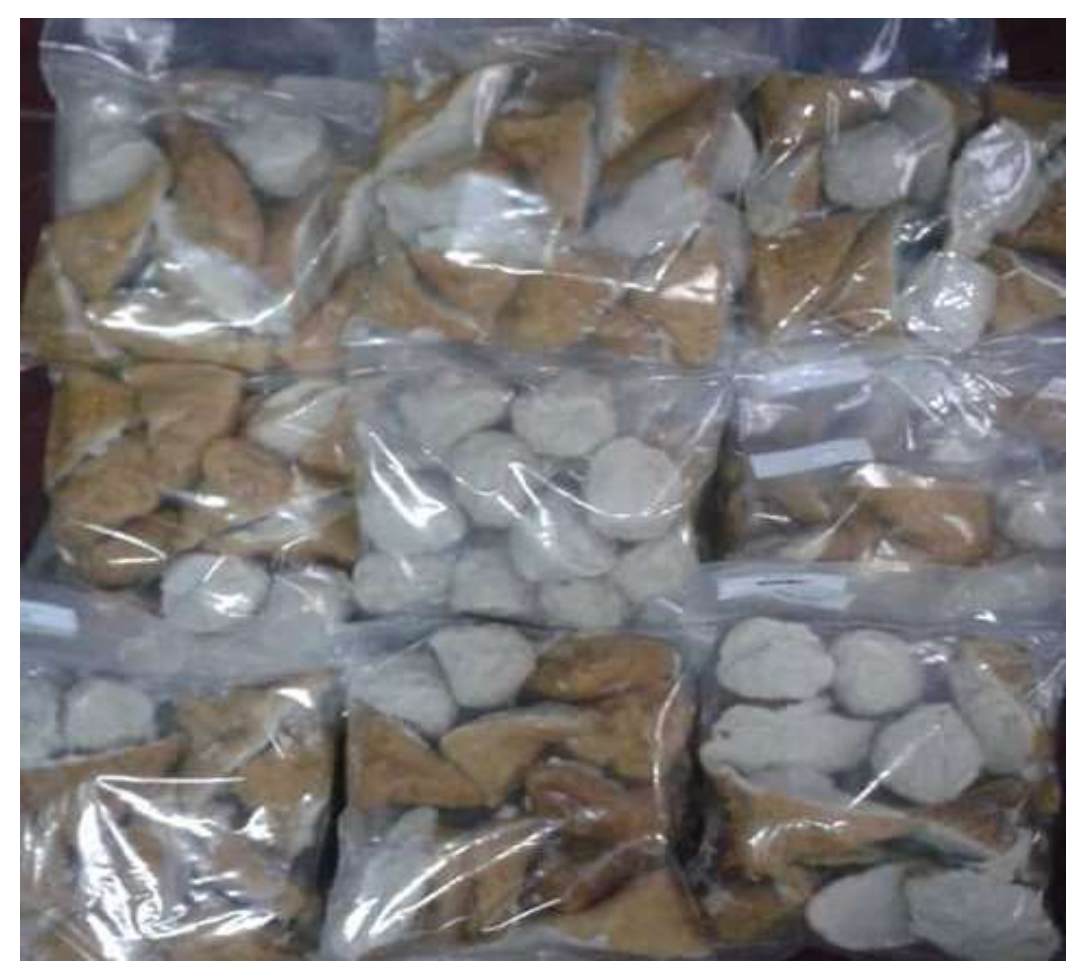

Gambar 2. Baksotahu Titianzhua

(Sumber. Titin Setiawati. 2015) 


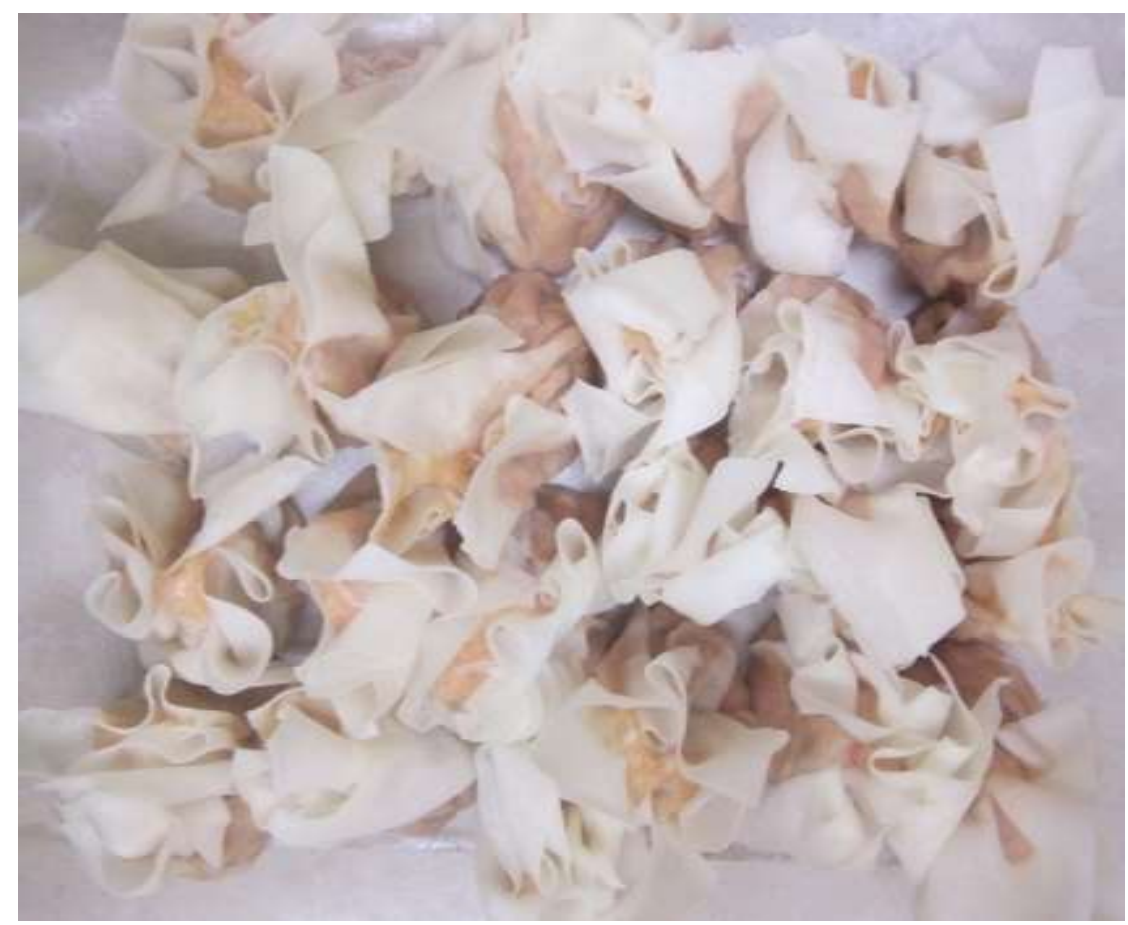

Gambar 3. Dimsum Titianzhua

(Sumber. Titin Setiawati. 2015)

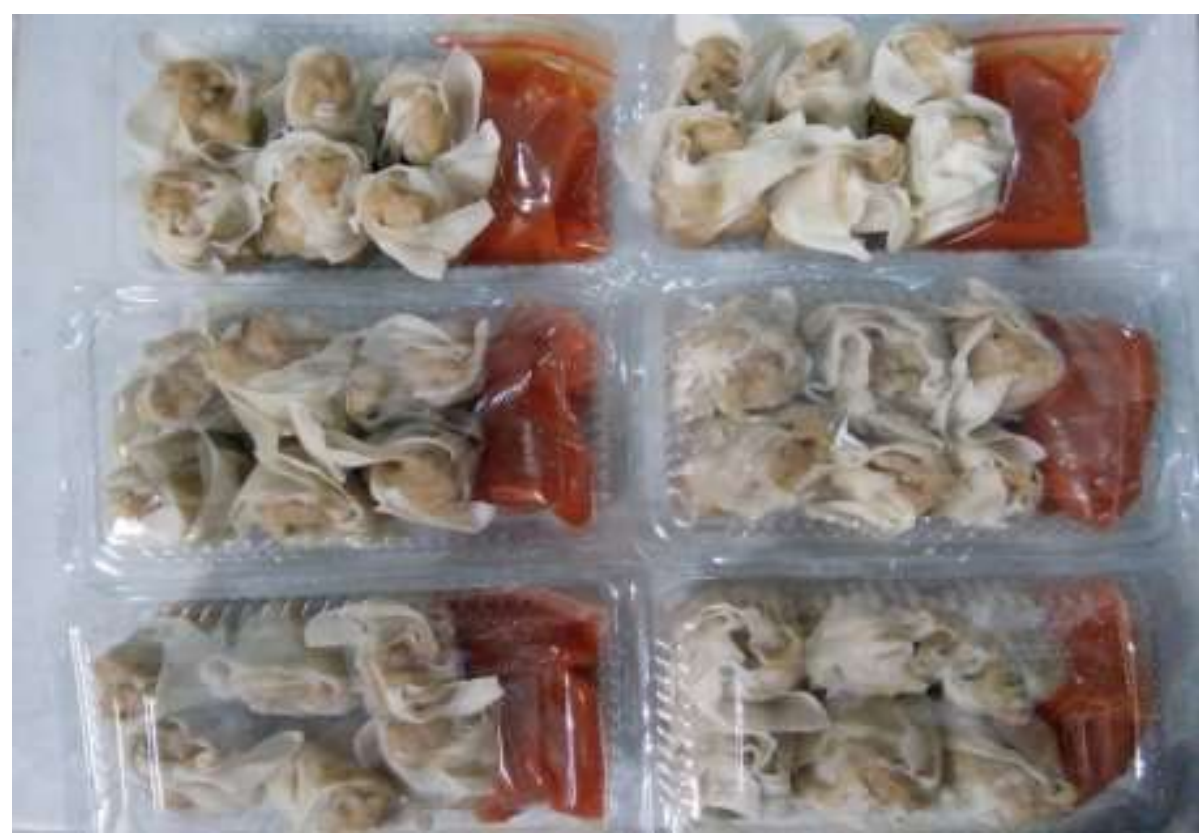

Gambar 4. Dimsum Titianzhua (Sumber. Titin Setiawati. 2015) 


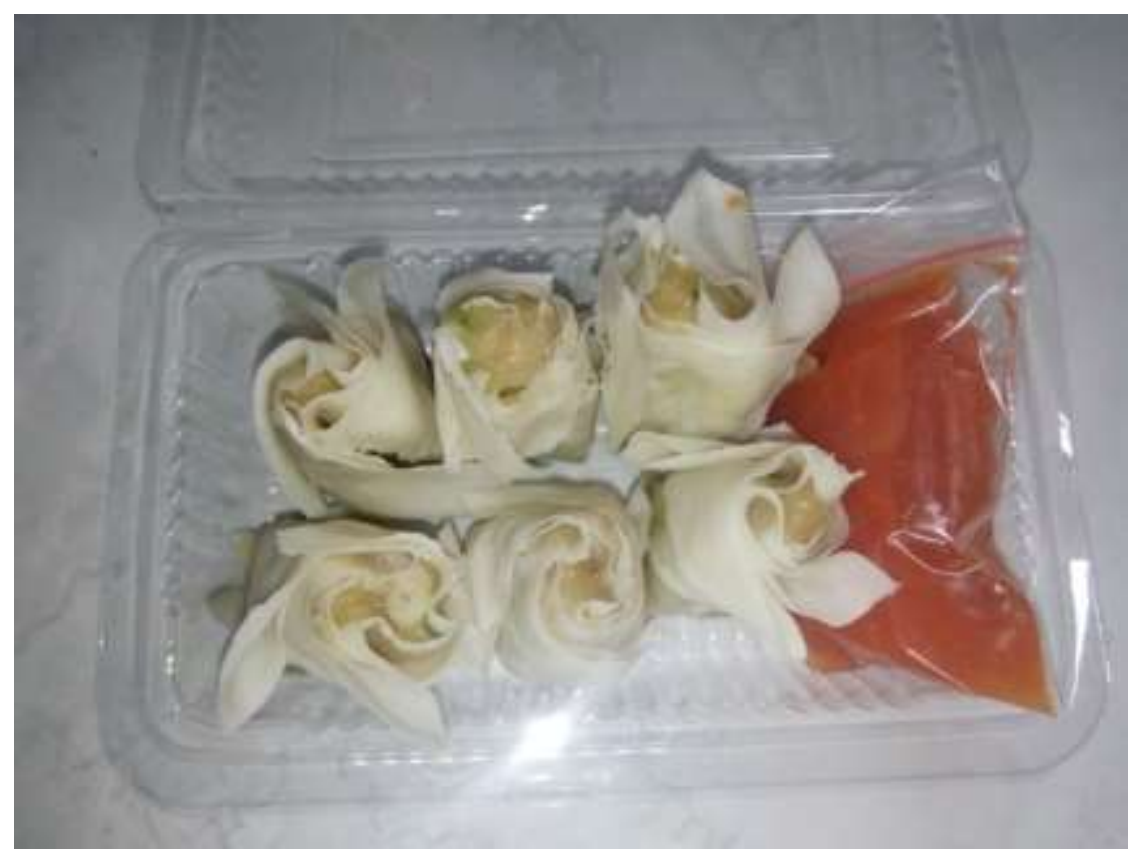

Gambar 5. Dimsum Titianzhua

(Sumber. Titin Setiawati. 2015)

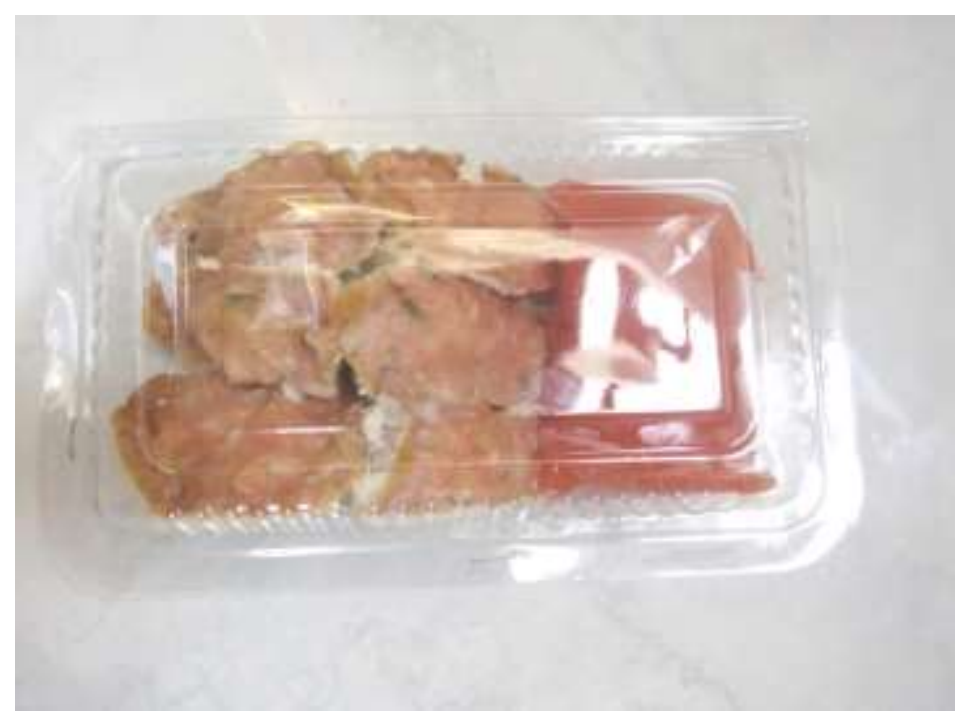

Gambar 6. Tahu Balik Titianzhua

(Sumber. Titin Setiawati. 2015) 


\section{d. Analisis Data}

Analisis masalah menggunakan 5W $1 \mathrm{H}$

- What : Perancangan Logo Dimsum Titianzhua,

- Where : Medan, Jalan Veteran Pasar Delapan Gang Melati

Nomor 096 Dusun Lima Desa Manunggal Helvetia

Medan,

- When : Saat ini,

- Who : Pemilik, karyawan dan pelanggan Dimsum Titianzhua,

- Why : Belum adanya Logo Dimsum Titianzhua,

- How : Dalam hal ini perancang akan membuat logo kemudian akan di aplikasikan ke dalam beberapa benda seperti pakaian kotak, bungkus plastik, kantong plastik dan lain-lain.

\section{III.4. VISUALISASI}

a. Typograpy

Tabel 1. Alternative Tipografi Headline

\begin{tabular}{|l|l|c|}
\hline \multicolumn{1}{|c|}{ BRANDNAME } & JENIS HURUF & STATUS \\
\hline TITIANZHUA & ALGERIAN & $X$ \\
\hline TITIANZHUA & Cooper Black & $X$ \\
\hline TITIANZHUA & Segoe Script & $X$ \\
\hline TITInחZHUA & & $\checkmark$ \\
\hline TITIANZ\#UA & Bouhous 93 & \\
\hline
\end{tabular}

(Sumber. Titin Setiawati. 2015) 
b. Sketsa

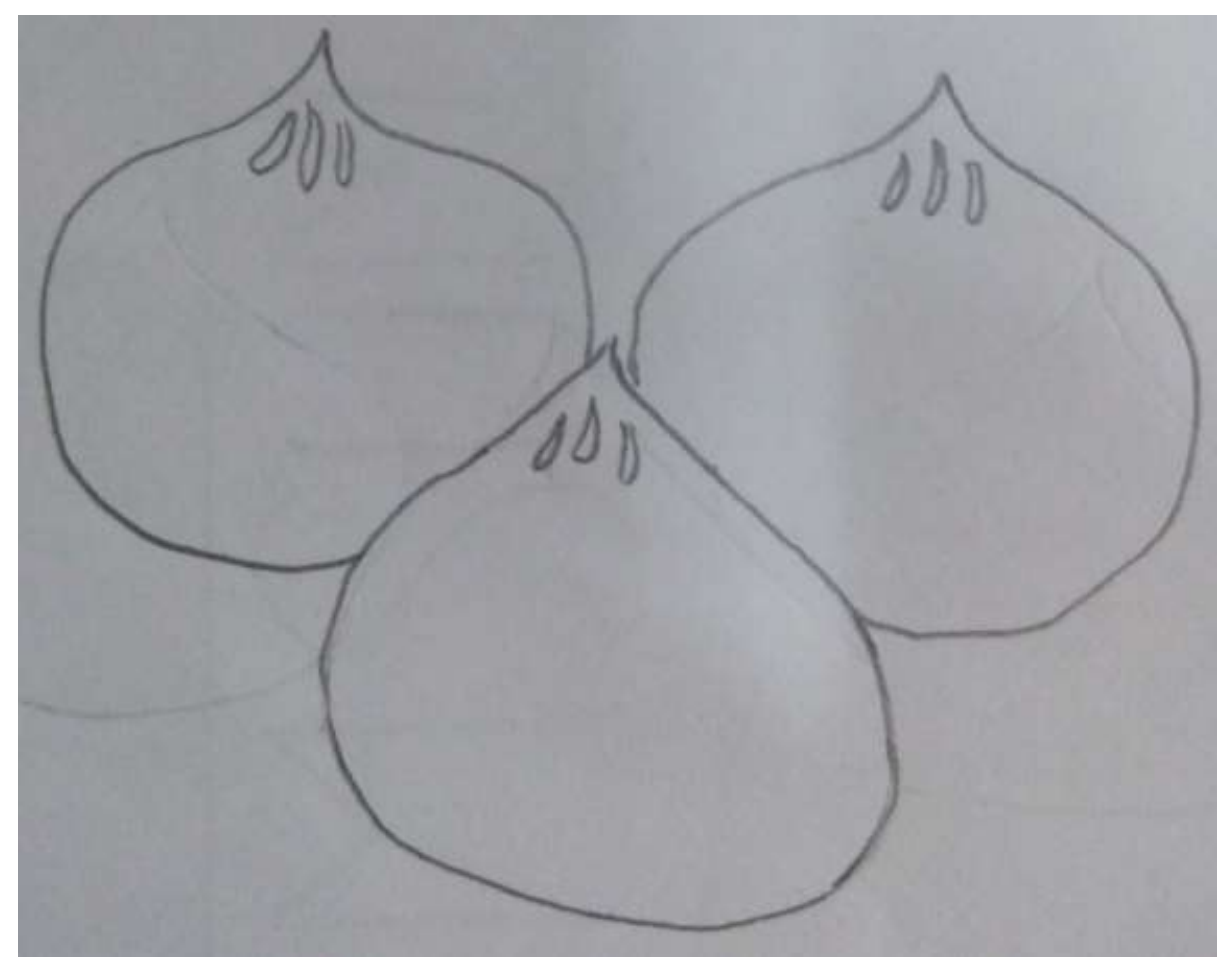

Gambar 7. Sketsa Dimsum dan Baksotahu Titianzhua (Sumber. Titin Setiawati. 2015)

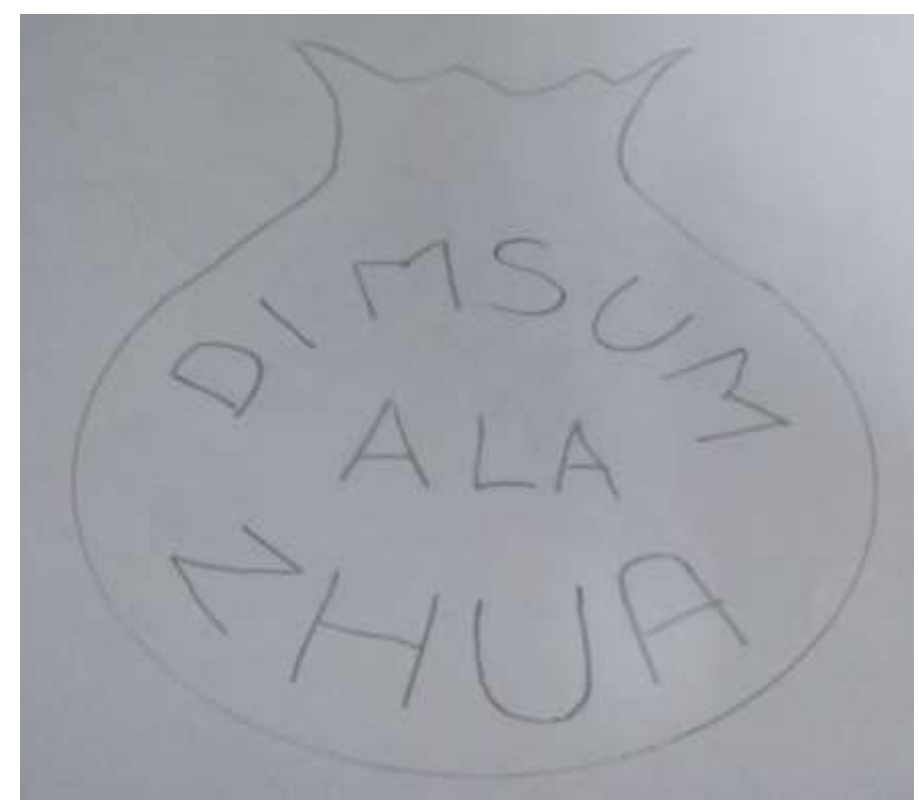

Gambar 8. Sketsa Dimsum dan Baksotahu Titianzhua (Sumber. Titin Setiawati. 2015) 


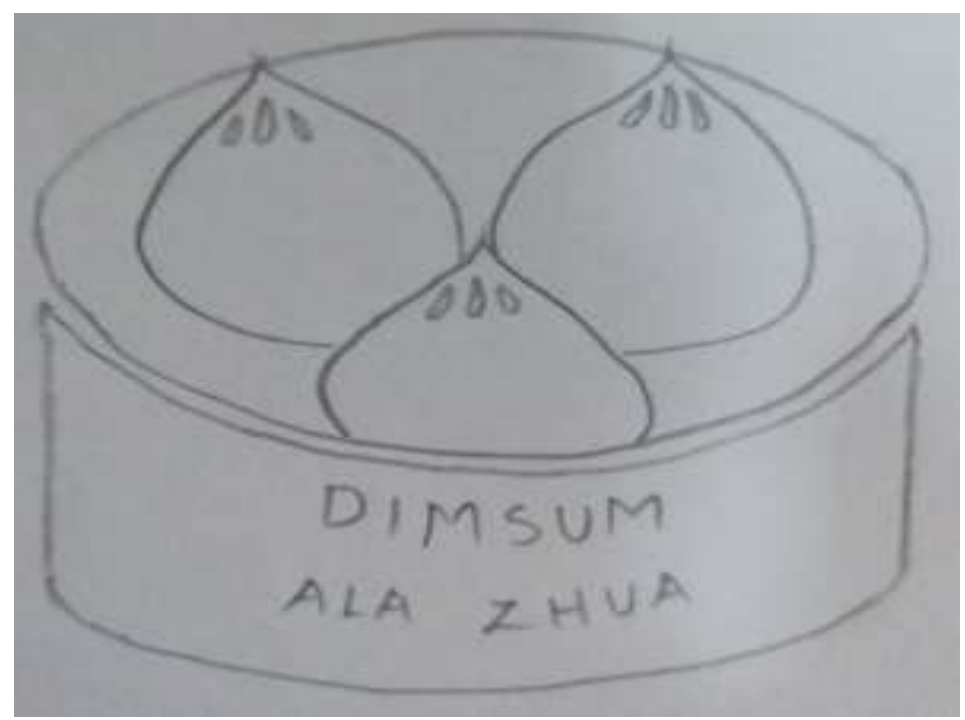

Gambar 9. Sketsa Dimsum dan Baksotahu Titianzhua (Sumber. Titin Setiawati. 2015)

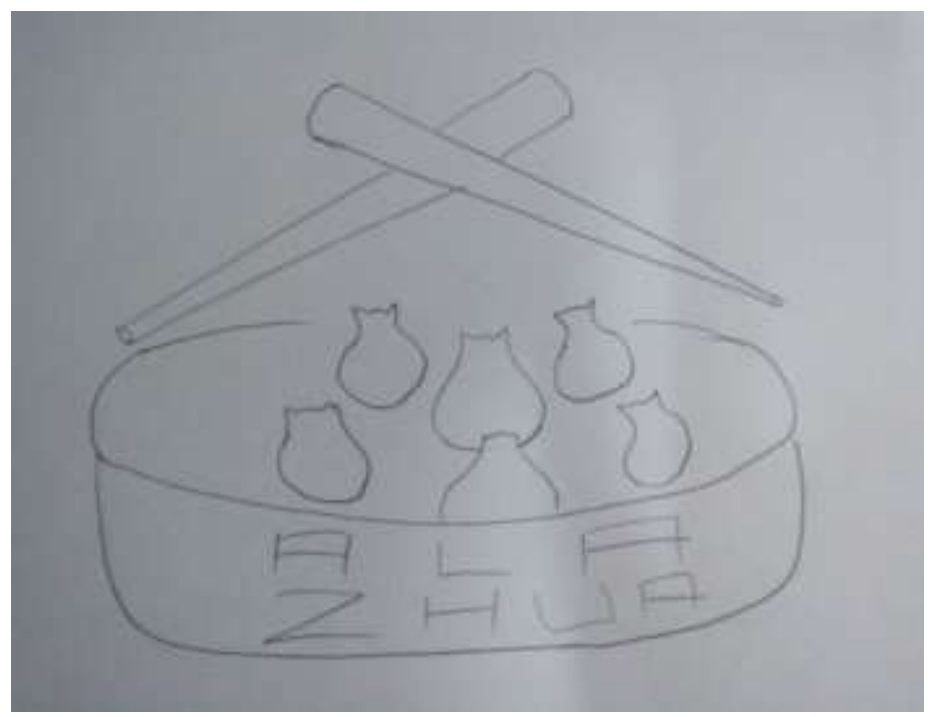

Gambar 10. Sketsa Dimsum dan Baksotahu Titianzhua (Sumber. Titin Setiawati. 2015) 
c. Desain Logo

(c)




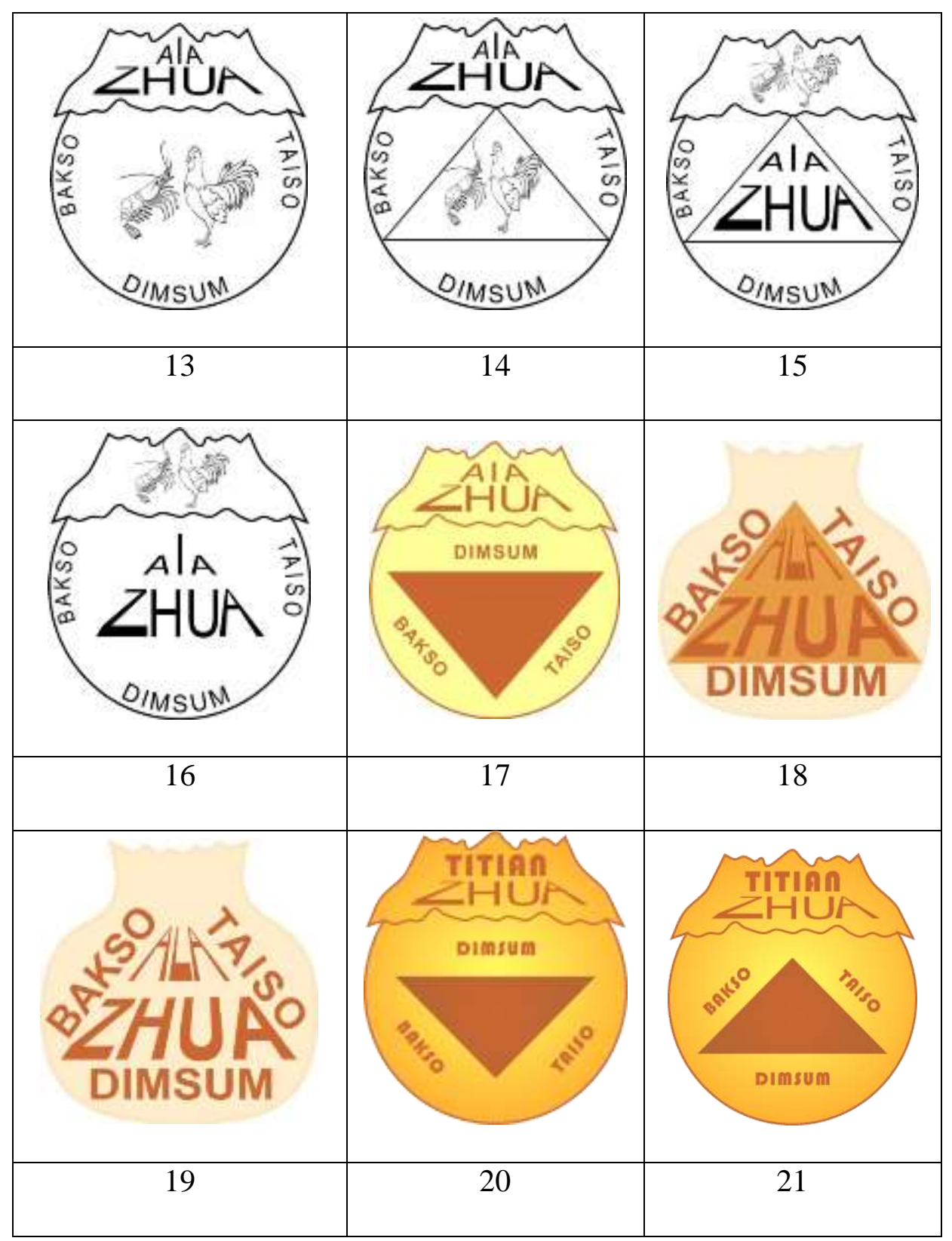




\section{d. Logo Terpilih}

\section{KESIMPULAN}

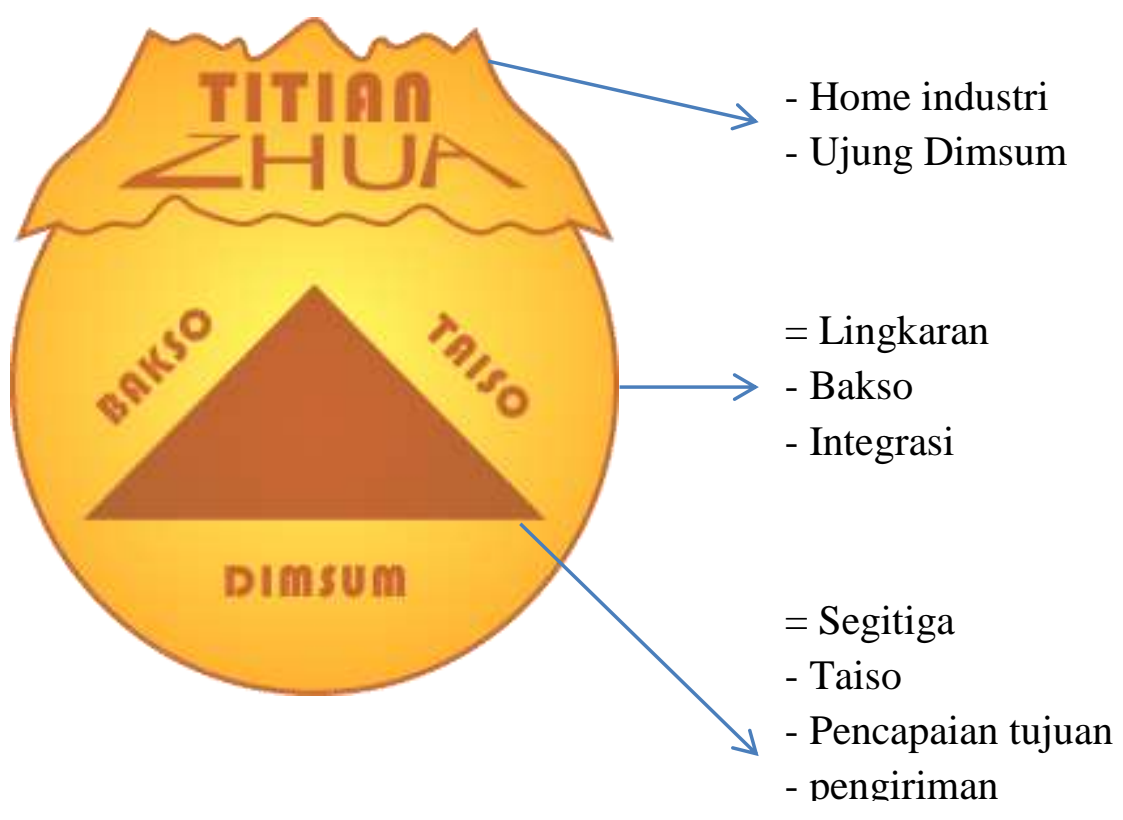

Dari penjelasan di atas maka dapat disimpulkan bahwa perancangan branding Logo adalah suatu upaya untuk mengenalkan produk kepada masyarakat agar brand yang kita miliki bisa dengan mudah di ingat oleh masyarakat, dan diharapkan dengan adanya logo yang sudah dibuat akan mempengaruhi sebuah informasi dan bisa membuat masyarakat semakin kenal terhadap usaha yang kita miliki.

Adapun saran - saran yang bisa diberikan adalah diharapkan agar perancangan logo tersebut tidak berhenti begitu saja, dan diharapkan terus mempromosikan usaha nya dengan baik.

\section{DAFTAR PUSTAKA}

[1] Alo Liliweri. (1992). Dasar-dasar Komunikasi Periklanan. Bandung: Citra Aditya Bakti

[2] Alexander,C. (1963). Pengertian Desain. Cammbridge. MA: Harvard University Press.

[3] Sachari, Agus. 2007. Pengertian Desain. Jakarta: Erlangga

[4] Surianto, Rustan. (2009). Mendesain Logo. Jakarta: PT. Gramedia Pustaka Utama 